\title{
A Morphometric Analysis of Pathological Alterations in Hemorrhoidal Disease Versus Normal Controls: A Controlled Trial
}

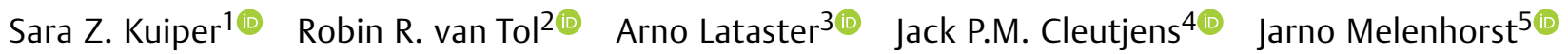 \\ Paul van Dijk ${ }^{3(0)}$ Sander M.J. van Kuijk ${ }^{6(1)}$ Stéphanie O. Breukink ${ }^{1,5,70}$
}

${ }^{1}$ Department of Surgery, School of Nutrition and Translation Research in Metabolism (NUTRIM), Maastricht University, Maastricht, The Netherlands

${ }^{2}$ Department of Surgery, Diakonessenhuis Medical Centre, Utrecht, The Netherlands

${ }^{3}$ Department of Anatomy and Embryology, Maastricht University,

Maastricht, The Netherlands

${ }^{4}$ Department of Pathology, Maastricht University Medical Centre and School for Cardiovascular Diseases (CARIM), Maastricht University, Maastricht, The Netherlands

${ }^{5}$ Department of Surgery, Maastricht University Medical Centre,

Maastricht, The Netherlands

${ }^{6}$ Department of Clinical Epidemiology and Medical Technology

Assessment, Maastricht University Medical Centre, Maastricht, The Netherlands

${ }^{7}$ Department of Surgery, School for Oncology and Developmental Biology (GROW), Maastricht University, Maastricht, The Netherlands
Address for correspondence Sara Z. Kuiper, MD, Universiteitssingel 50, 6229 ER, Maastricht, The Netherlands (e-mail: s.kuiper@maastrichtuniversity.nl).

J Coloproctol 2022;42(2):140-145.
Abstract

\section{Keywords}
- hemorrhoidal disease
- hemorrhoids
- collagen
- morphometrics

Objective Until today, the true pathophysiology of hemorrhoidal disease (HD) has not yet been unraveled. More and more evidence guides us towards the hypothesis that reduced connective tissue stability is associated with a higher incidence of hemorrhoids. The present study aimed to compare the quantity and quality of collagen, and vessel morphometrics, in patients with symptomatic HD compared with normal controls.

Methods Twenty-two samples of grade III and grade IV HD tissue from patients undergoing a hemorrhoidectomy between January 2004 and June 2015 were included in the study group. Samples of 15 individuals without symptomatic HD who donated their body to science and died a natural death served as controls. The quantity and quality of anal collagen, and anal vessel morphometrics were objectified. The quality of collagen was subdivided in young (immature) and old (mature) collagen.

Results Patients with HD had an increased percentage of total anal collagen (62.1 \pm 13.8 versus $18.7 \pm 14.5 \% ; \quad p=0.0001)$, a decreased percentage of young collagen $(0.00009 \pm 0.00008$ versus $0.0008 \pm 0.0008 \% ; p=0.001)$, and a smaller surface area of the anal vessels $\left(795.1 \pm 1215.9\right.$ micrometre $^{2}$ versus $\left.1219.0 \pm 1976.1 ; p=0.003\right)$ compared with controls. The percentage of old collagen did not differ between the control and study groups $(0.588 \pm 0.286 \%$ versus $0.389 \pm 0.242 \% ; p=0.06)$. received

August 10, 2021

accepted after revision

October 25, 2021

published online

February 2, 2022
DOI https://doi.org/

10.1055/s-0041-1742257.

ISSN 2237-9363.

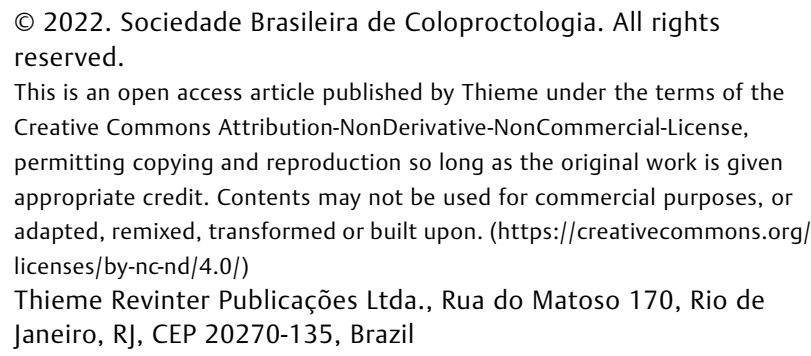

(c) 2022. Sociedade Brasileira de Coloproctologia. All rights reserved.

This is an open access article published by Thieme under the terms of the Creative Commons Attribution-NonDerivative-NonCommercial-License, permitting copying and reproduction so long as the original work is given appropriate credit. Contents may not be used for commercial purposes, or adapted, remixed, transformed or built upon. (https://creativecommons.org/ licenses/by-nc-nd/4.0/)

Thieme Revinter Publicações Ltda., Rua do Matoso 170, Rio de Janeiro, RJ, CEP 20270-135, Brazil 
Conclusion The outcomes of the present study suggest that alterations in anal collagen composition may play a role in the formation of hemorrhoids.

\section{Introduction}

Hemorrhoidal disease (HD) has a high prevalence in the Western world, affecting about one third of the population. ${ }^{1}$ Despite the high prevalence and a large body of research, the etiology and pathogenesis of HD has not yet been fully unraveled.

Hemorrhoids are normal vascular cushions filled with arterial-venous blood vessels and are present in the submucosa of the anal canal. The expansion of the vascular cushions is important in providing a watertight seal to the anus and plays a paramount role in establishing fecal continence. ${ }^{2}$ Hemorrhoids become a disease when the size of the hemorrhoidal complex enlarges in a pathological way and may result in symptoms like pain, blood loss, and/or prolapse. ${ }^{3}$ Hemorrhoids are mostly classified by the severity of prolapse according to the grading system of Goligher et al. ${ }^{4-8}$

Until now, the exact pathophysiology of hemorrhoids remains unraveled, and several theories are reported. The most widely accepted theory describes that the prolapse of the hemorrhoidal plexus is initiated by a temporary return insufficiency of the anal vascular system. ${ }^{9,10}$ In case the return is hampered, progressive vascular dilation and hemorrhoidal hyperplasia will occur, paving the way for hemorrhoidal prolapse. ${ }^{11}$

Besides, more and more evidence guides us towards the hypothesis that histological alterations, that is, degeneration, of the hemorrhoidal plexus during aging play a role in the development of HD. ${ }^{1,12,13}$ The hemorrhoidal plexus is surrounded by a web of connective tissue, composed of collagen, fibroelastic tissue, and muscle fibres. ${ }^{14,15}$ The various fibers, sheets, and networks made of collagens are all extremely strong and resistant to normal shearing and tearing forces. ${ }^{16}$ Degeneration of these fibrous elements and alterations in collagen metabolism may lead to destruction and loss of this supporting tissue.

Specific staining by Sirius Red (SR) is one of the most important stains to study collagen networks in different tissues. Under polarized light, stained collagen bundles appear green, red, or yellow. Polarizing light microscopy produces an image only of material having repetitive, periodic macromolecular structure; features without this structure are not seen. Since collagen fibers fulfil these requirements, they are easily differentiated from the background, allowing for quantitative morphometric analysis. ${ }^{17}$ The young collagen fibers color yellow to green in comparison to the old fibers that appear orange to red by polarized light. ${ }^{18}$ The difference between these histological characteristics is based on the number of crosslinks, which are abundant in mature collagen and lack in juvenile collagen. Thin young green collagen can be interpreted as type III collagen, and thick red collagen can be seen as old type I collagen. However, these interpretations should be made with precaution since we speak of spectra of colors which can overlap between the two types of collagens. ${ }^{19}$ Therefore, in the present article, we chose to use the wording young collagen for yellow/green collagen that lacks crosslinking and old collagen for orange/red collagen rich in crosslinks.

In 2010, Willis et al. postulated that less connective tissue is associated with a higher incidence of hemorrhoids. ${ }^{13}$ They found that disturbances in collagen I/III and in collagen/protein ratios lead to reduced connective tissue stability. Furthermore, loss of connective tissue may result in dilation of supplying blood vessels, modifying the normal vascular anatomy.

Up to now, scarce reliable data exist on possible abnormalities in collagen composition in HD. Therefore, the aim of the present morphometric study was to determine the quantity and quality of collagen in patients with HD versus healthy controls, and to reconsider the morphometrics of anal vascular structures in patients with HD.

\section{Materials and Methods}

\section{Patients, donors, and recruitment}

Patients with internal symptomatic HD grade III or IV who underwent standard hemorrhoidectomies between January 2004 and June 2015 were included in the study group. During a hemorrhoidectomy, an elliptical incision was made in the hemorrhoidal tissue extending proximally through the dentate line to the upper limit of the hemorrhoid. ${ }^{20}$ The surgeon excised the hemorrhoidal tissue including the mucosa and/or part of the perianal skin. ${ }^{21,22}$ Only patients $>18$ years old with primary or recurrent HD were included. Patients who had undergone Longo procedures or any other major anorectal surgery were excluded from the study. ${ }^{23}$ Further exclusion criteria were malignancies, aortic aneurysms, hernias, varicose or other connective tissue diseases, patients on corticosteroid-, cytostatic- or radiotherapy, and concomitant anorectal diseases (fistula, abscess, fissure, or polyps).

The resected hemorrhoidal specimens were fixed in $10 \%$ buffered formalin immediately after the operation and were processed to embed in paraffin for further investigation.

The control group consisted of individuals who had donated their body to the department of Anatomy and Embryology of Maastricht University and who had died of a natural death between December 2016 and June 2018. Handwritten and signed codicils from the donors, as required by the Dutch law, are kept at the Department of Anatomy and Embryology. In the review of the past medical histories of these cadavers, symptomatic HD, as well as the aforementioned exclusion criteria, were never listed as a condition they had. In these cadavers, the pelvis was medially sawed through, leaving the halved rectoanal area. After trimming, 
the emerged specimens were fixed in $10 \%$ buffered formalin and processed to embed in paraffin.

The patients included in the control group gave premortem permission to use bodily tissue in name of education and research. All patients included in the study group gave their consent to undergo hemorrhoidectomy. Ethical clearance for the present study and approval to use the resected specimens was obtained from the Maastricht University Medical Centre ethical review board (file number 2017-0065).

\section{Collagen Quantity and Quality}

Collagen quantity was analyzed by collagen/total tissue ratio estimating the relative amount of collagen. The quality of the collagen was analyzed by calculating the amount of new collagen and the amount of old collagen.

The paraffin blocks were cut with a microtome (Leica 2245, Nussloch, Germany) and the $5 \mu \mathrm{m}$ thick sections were mounted on coated glass slides. After the paraffin was removed, serial sections of each specimen were stained with hematoxylin and eosin (HE) and Sirius Red (SR) according to the protocol of the local laboratory. For HE, this entailed staining for 5 minutes with HE stains (Mayer Hematoxylin/Eosin protocol), and for SR, the stain was applied by staining for 30 minutes with SR $(0.1 \%$ of SR in saturated aqueous picric acid).

Hematoxylin has a deep blue-purple color that attaches to nucleic acids and stains nucleic blue. Eosin stains cytoplasm and extracellular matrix with varying degrees of pink. ${ }^{24}$ Sirius Red is a strong dye that identifies fibrillary collagen networks in tissue sections. ${ }^{25,26}$

The SR-stained sections were observed with a microscope (Leica-DM4B, Nussloch, Germany) with a 20-time objective. Pictures were made with normal and polarized light, creating images of the same areas under the same conditions (exposure time of 17.8 milliseconds versus 300 milliseconds).

Using a designed computer program (Leica Qwin, Cambridge, UK), the red stained collagen was detected on the bright field image. Within this mask, the color of the birefringence polarized collagen fibers was determined by the hue, saturation, and intensity settings that determined the different color aspects of the birefringence collagen fibers. The colors ranged from red, orange, yellow, and green to teal. The same parameters defining threshold bands of hue, saturation, and brightness were applied to all the images. ${ }^{19}$

Using polarized light, a distinction can be made between relatively new collagen, which appears as green to yellow, and adult collagen, which appears as orange to red.

Collagen quantity is expressed as the percentage of collagen relative to the total amount of tissue. The quality of the collagen is expressed as the percentage of new collagen and the percentage of adult collagen relative to the total amount of tissue. ${ }^{12}$

\section{Structural Vascular Alterations}

Structural vascular alterations were estimated by the dilatation of the anal vessels comparing HD patients with healthy controls. The perimeter of the anal vessel was calculated using platelet-endothelial cell adhesion molecule 1 (CD31) endothelial antibody staining. Platelet-endothelial cell adhesion molecule 1 is a transmembrane glycoprotein with various functions in multiple physiologic and pathologic pathways, and a very specific marker for endothelial cells. ${ }^{27}$ The monoclonal anti-CD31 antibody recognizes a fixationresistant epitope in endothelial cells. ${ }^{28}$

Serial sections of each specimen were stained with CD31 endothelial antibody staining (DAKO-M0823, dilution $1: 100)$. After incubation, only the sections with distinct membranous labelling for $\mathrm{CD} 31$ were taken into the analysis. Pictures of the sections with CD31 were uploaded on the computer and examined manually. The spaces surrounded by the CD31 staining were considered vessels. Both arteries and venules were taken into account. The demarcation of the vessel surface indicated by the CD31 stained endothelial cells was noted and integrated in a computer algorithm for analysis. Anal vascular morphometrics were specified into surface area, perimeter, and aspect of the vessel. The aspect of the vessel is a ratio and is calculated by dividing the length of the vessel by the width of the vessel. The surface area of the vessel is expressed in square micrometers (micrometer ${ }^{2}$ ), the perimeter of the vessel is expressed in micrometers, and the aspect of the vessel has no dimension (ratio).

\section{Statistics}

All statistical analyses were performed using IBM SPSS Statistics for Windows version 25.0 (IBM Corp., Armonk, NY, USA). Normal distribution was assumed after performing the Shapiro-Wilk test. Multiple linear regression analysis was used to adjust for baseline difference. Data were expressed as means \pm standard deviation (SD). Correlations between age and the percentage collagen were expressed as Pearson correlation coefficient $R$. A $p$-value $<0.05$ was considered statistically significant.

\section{Results}

\section{Patients, Donors and Recruitment}

The study group consisted of 22 patients who underwent a hemorrhoidectomy. The mean age of the study group was 55.6 (31 to 78) years old, with a male to female ratio of 15:7. The control group entailed 15 specimens with a significantly different mean age of 82.7 (60 to 95) years old. The male to female ratio in the control group was 8:7.

\section{-Table 1}

\section{Collagen Quantity and Quality}

The mean percentage of total collagen was higher in patients with hemorrhoidal disease $(62.1 \pm 13.8 \%)$ than in the control group ( $18.7 \pm 14.5 \% ; p=0.0001)$. There was no difference in the mean percentage of collagen between males and females $(50.3 \pm 24.4$ versus $34.9 \pm 25.7$ micrometers; $p=0.08)$. Regression analysis showed that a higher age did not influence the percentage of collagen $(R=0.86)$.

The percentage of young collagen was higher in the control group $(0.0008 \pm 0.0008 \%)$ than in the study group $(0.00009 \pm 0.00008 \% ; p=0.001)$. The percentage of old collagen did not differ significantly between the control group 
Table 1 A direct comparison of study versus control groups regarding collagen percentage, with an asterisk indicating statistical significance

\begin{tabular}{|l|l|l|l|l|l|l|l|l|}
\hline & $\begin{array}{l}\text { M:F } \\
\text { ratio }\end{array}$ & $\begin{array}{l}\text { Mean age } \\
\text { in years } \\
\text { (range) }\end{array}$ & $\begin{array}{l}\text { Percentage of } \\
\text { collagen of } \\
\text { total tissue }\end{array}$ & $\begin{array}{l}\text { p-value } \\
\text { (percentage } \\
\text { of collagen) }\end{array}$ & $\begin{array}{l}\text { Percentage } \\
\text { of young } \\
\text { collagen }\end{array}$ & $\begin{array}{l}\text { p-value } \\
\text { (young } \\
\text { collagen) }\end{array}$ & $\begin{array}{l}\text { Percentage } \\
\text { of old } \\
\text { collagen }\end{array}$ & $\begin{array}{l}p \text {-value } \\
\text { (old collagen) }\end{array}$ \\
\hline $\begin{array}{l}\text { Study } \\
(n=22)\end{array}$ & $15: 7$ & $\begin{array}{l}55.6 \\
(31-78)\end{array}$ & $\begin{array}{l}62.1 \\
\pm 13.8\end{array}$ & $0.0001^{*}$ & $\begin{array}{l}0.00009 \\
\pm 0.00008\end{array}$ & $0.001^{*}$ & $\begin{array}{l}0.389 \\
\pm 0.242\end{array}$ & 0.06 \\
\hline $\begin{array}{l}\text { Control } \\
(n=15)\end{array}$ & $8: 7$ & $\begin{array}{l}82.7 \\
(60-95)\end{array}$ & $\begin{array}{l}18.7 \\
\pm 14.5\end{array}$ & & $\begin{array}{l}0.0008 \\
\pm 0.0008\end{array}$ & & 0.588 \\
\pm 0.286
\end{tabular}

Abbreviations: F, females; M, males.

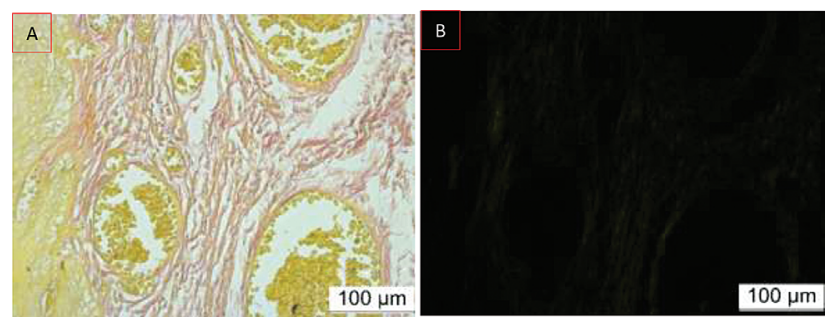

Fig. 1 (A) Sirius Red staining under normal light, indicating the relationship of young collagen (yellow to green) versus old collagen (orange to red) in a healthy control individual. (B) Sirius Red staining under polarized light, indicating the relationship of young collagen (yellow to green) versus old collagen (orange to red) in a healthy control individual'.
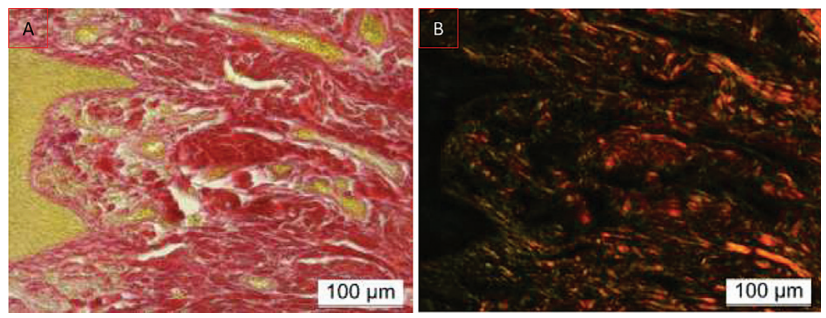

Fig. 2 (A) Sirius Red staining under normal light, indicating the relationship of young collagen (yellow to green) versus old collagen (orange to red) in a patient with hemorrhoidal disease. (B) Sirius Red staining under polarized light, indicating the relationship of young collagen (yellow to green) versus old collagen (orange to red) in a patient with hemorrhoidal disease.

$(0.588 \pm 0.286 \%)$ and the study group $(0.389 \pm 0.242 \%$; $p=0.06)$.

\section{Structural Vascular Alteration}

A direct comparison showed a difference in the surface area of the vessels between the study group ( $795.1 \pm 1215.9$ micrometer $\left.^{2}\right)$ and the control group (1219.0 \pm 1976.1 micrometer $^{2}$; $p=0.003)$. The perimeter of the vessel was not different between the study group $(131.7 \pm 110.8$ micrometers $)$ and the control group ( $149.0 \pm 117.3$ micrometers; $p=0.12$ ). The aspect of the vessel appeared larger in the study group compared with the control group $(3.10 \pm 7.5$ versus $2.16 \pm 1.1$, respectively; $p=0.02$ ).

\section{-Table 2}

\section{Discussion and Conclusion}

The present study demonstrated that patients with hemorrhoids had increased total collagen, decreased young collagen, and smaller surface area of the anal vessels compared with healthy controls.

In other studies that examined the role of collagen in HD, an association was found between reduced connective tissue stability and an increase in the incidence of HD. ${ }^{12,13}$ However, the present study revealed a higher percentage of total collagen in patients with HD, suggesting ample connective tissue stability in this group. The mean age of the control group was significantly higher than that of the study group. The literature reports that the total amount of collagen reduces when you get older. ${ }^{29}$ However, the higher mean age in the control group cannot function as an explanation for this outcome because the regression analysis showed that age does not influence the percentage of collagen. Nonetheless, it has to be noted that the small sample size of the present study could have affected the regression analysis. In the present study, we found that patients with HD have an increased percentage of total collagen. Multiple studies have reported elevated resting pressure in patients with hemorrhoids, which could result in vascular stretching. ${ }^{30}$ Mechanical vascular stretching has shown to stimulate collagen synthesis. ${ }^{31}$ A possible hypothesis for the increased percentage of total collagen in HD could be a result of the expanded vessel walls.

Table 2 A direct comparison of study versus control groups regarding vessel data, with an asterisk indicating statistical significance

\begin{tabular}{|l|l|l|l|l|l|l|}
\hline & $\begin{array}{l}\text { Surface } \\
\text { vessel in } \\
\text { micrometer }\end{array}$ & $\begin{array}{l}p \text {-value } \\
\text { (surface } \\
\text { vessel) }\end{array}$ & $\begin{array}{l}\text { Perimeter } \\
\text { vessel in } \\
\text { micrometer }\end{array}$ & $\begin{array}{l}\text { p-value } \\
\text { (perimeter } \\
\text { vessel) }\end{array}$ & $\begin{array}{l}\text { Aspect } \\
\text { vessel } \\
\text { (aspect } \\
\text { vessel) }\end{array}$ \\
\hline $\begin{array}{l}\text { Study } \\
(n=22)\end{array}$ & $795.1 \pm 1215.9$ & $0.003^{*}$ & $\begin{array}{l}131.7 \\
\pm 110.8\end{array}$ & 0.12 & $\begin{array}{l}3.10 \\
\pm 7.5\end{array}$ & $0.02^{*}$ \\
\hline $\begin{array}{l}\text { Control } \\
(n=15)\end{array}$ & $1219.0 \pm 1976.1$ & & $\begin{array}{l}149.0 \\
\pm 117.3\end{array}$ & & $\begin{array}{l}2.16 \\
\pm 1.1\end{array}$ \\
\hline
\end{tabular}


Furthermore, the present study showed that patients with HD have a lower percentage of young collagen. This finding is not in line with previous research by both Willes et al. and Nasseri et al., who demonstrated that patients with HD have a decreased type I/III ratio. These studies made the direct interpretation of orange/red shades being old collagen I and yellow/green tints as young collagen type III. ${ }^{12,13}$ In the present study, we made the distinction between young and old collagen. Young thin collagen fibers appear yellow to green while old thick fibers appear orange to red. ${ }^{18} \mathrm{~A}$ decreased percentage of young collagen implies a decreased amount of crosslinking and, therefore, could lead to a reduced mechanical stability of connective tissue in the hemorrhoidal complex. Nevertheless, the total amount of collagen was higher in HD patients and a statistically significant difference does not imply that the finding is clinically significant. Furthermore, a direct comparison of collagen percentages cannot be made, since these studies only reported the ratio of the parameters and not the separate percentages.

A closer look into alterations in anal vascular structures showed an increase in the surface area and in the aspect of the vessel in healthy controls compared with patients with HD. Remarkably, the comparative data on vessel perimeter does not appear to be of significant difference between the two groups. It is postulated that the malfunctioning hemorrhoidal complex in HD could lead to the distention of vessels. However, the distention of the vessels was greater in healthy controls. This could be explained by the effect of a lifelong erect posture among the latter. ${ }^{32}$ Furthermore, it must be considered that the controls originate from postmortem bodies that are spouted under pressure (between 0.2 and $0.3 \mathrm{Atm}$ ) with a formalin mixture in the femoral artery. This process leads to a visible distension of the vessels.

One of the limitations of the present study is the relatively small number of patients in both groups. Nevertheless, it is quite difficult to obtain specimens from hemorrhoidectomy operations while taking the various inclusion and exclusion criteria into consideration. The same accounts for the specimens from the control group, which has also shown to be a difficulty in previous pathology studies. ${ }^{12,13}$ Furthermore, the medical history of the control group does not mention HD, albeit people can suffer from HD without reporting this to their medical doctor. Another aspect of the present study that could diminish the power of the evidence is the difference between the study group and the control group. The groups differ both significantly in the male to female ratio and in the mean age. The amount and nature of collagen are likely to be influenced by age. In a small study, this can possibly give rise to bias. However, making use of a regression analysis can give insight in possible confounders and help to correct for them.

The final limitation of the present study is that both arteries and venules were taken into account when estimating the structural vascular alterations. The CD31 is a transmembrane glycoprotein that is present in the endothelium of arteries and veins. As a result, we were not able to make a distinction between these vessels. However, we were interested in a mean increase of diameter of the vessels overall. Since we calculated the diameter of arteries and veins in both groups, a possible difference between the groups will be corrected.

The main strength of the present study lies in the fact that it can assist in unravelling the true pathophysiology of HD by further considering the involvement of alterations in collagen composition and in the anal vascular structure. Translating the findings of the present study to the clinical practice can contribute to optimize the care for patients with HD.

Although multiple options are available for the treatment of HD, the holy grail has not been found yet and many patients with HD are still seeking for their ideal cure. Therefore, it is important to have a better understanding of the pathophysiology of $\mathrm{HD}$ and of the different mechanisms involved. The results of the present study suggest that collagen can play a role in the formation of hemorrhoids. Still, the relationship between collagen and downregulation of protein synthesis demands further exploration. The reduced amount of young collagen in HD patients could be of interest for promising mechanisms in HD treatments. For example, the use of hyaluronic acid to improve remodeling of extracellular matrix is increasing in popularity. ${ }^{33}$ Nevertheless, one must keep in mind that the disease underlying hemorrhoids is multifactorial and that further research on this societal burden has to be performed.

\section{Ethics Approval}

Ethical clearance for the present study was obtained from the Maastricht University Medical Centre ethical review board (file number 2017-0065).

\section{Consent to Participate}

Informed consent was obtained from all individual participants included in the present study.

\section{Consent for Publication}

Not applicable.

\section{Availability of Data and Material}

Available on special request.

\section{Code Availability}

Not applicable.

\section{Contributions of the Authors}

All authors whose names appear on the submission (1) made substantial contributions to the conception or design of the work; or to the acquisition, analysis, or interpretation of data; (2) drafted the work or revised it critically for important intellectual content; (3) approved the version to be published; and (4) agree to be accountable for all aspects of the work in ensuring that questions related to the accuracy or integrity of any part of the work are appropriately investigated and resolved.

\section{Funding}

No funding was received for conducting the present study. 


\section{Conflict of Interests}

The authors have no conflict of interests to declare.

\section{Acknowledgements}

The authors thank Prof. A. Zur Hausen, Department of Pathology, Maastricht University Medical Centre, for supporting the present study by preparing the sections after hemorrhoidectomy.

\section{References}

1 Loder PB, Kamm MA, Nicholls RJ, Phillips RK. Haemorrhoids: pathology, pathophysiology and aetiology. Br J Surg 1994;81 (07):946-954

2 Abramowitz L, Weyandt GH, Havlickova B, et al. The diagnosis and management of haemorrhoidal disease from a global perspective. Aliment Pharmacol Ther 2010;31(Suppl 1):1-58

3 van Tol RR, van Zwietering E, Kleijnen J, et al. Towards a core outcome set for hemorrhoidal disease-a systematic review of outcomes reported in literature. Int J Colorectal Dis 2018;33(07): 849-856

4 Banov L Jr, Knoepp LF Jr, Erdman LH, Alia RT. Management of hemorrhoidal disease. J S C Med Assoc 1985;81(07):398-401

5 Elbetti C, Giani I, Novelli E, Fucini C, Martellucci J. The single pile classification: a new tool for the classification of haemorrhoidal disease and the comparison of treatment results. Updates Surg 2015;67(04):421-426

6 Goligher JC, Duthie HL, Nixon HH. Surgery of the anus, rectum, and colon. 3rd ed. London: Baillière Tindall; 1975

7 Sun Z, Migaly J. Review of Hemorrhoid Disease: Presentation and Management. Clin Colon Rectal Surg 2016;29(01):22-29

8 Gaj F, Trecca A, Busotti A, Brugiotti C, Carboni M. The new classification of hemorrhoids: PATE 2000-Sorrento. History of the scientific debate. Minerva Chir 2002;57(03):331-339

9 Haas PA, Fox TA Jr, Haas GP. The pathogenesis of hemorrhoids. Dis Colon Rectum 1984;27(07):442-450

10 Thomson WH. The nature of haemorrhoids. Br J Surg 1975;62 (07):542-552

11 Aigner F, Gruber H, Conrad F, et al. Revised morphology and hemodynamics of the anorectal vascular plexus: impact on the course of hemorrhoidal disease. Int J Colorectal Dis 2009;24(01): 105-113

12 Nasseri YY, Krott E, Van Groningen KM, et al. Abnormalities in collagen composition may contribute to the pathogenesis of hemorrhoids: morphometric analysis. Tech Coloproctol 2015; 19(02):83-87

13 Willis S, Junge K, Ebrahimi R, Prescher A, Schumpelick V. Haemorrhoids - a collagen disease? Colorectal Dis 2010;12(12):1249-1253

14 Alonso-Coello P, Mills E, Heels-Ansdell D, et al. Fiber for the treatment of hemorrhoids complications: a systematic review and meta-analysis. Am J Gastroenterol 2006;101(01):181-188

15 Burkitt DP, Graham-Stewart CW. Haemorrhoids-postulated pathogenesis and proposed prevention. Postgrad Med J 1975;51(599): 631-636

16 Mescher AL. Junqueira's basic histology : text and atlas. 2018
17 Lattouf R, Younes R, Lutomski D, et al. Picrosirius red staining: a useful tool to appraise collagen networks in normal and pathological tissues. J Histochem Cytochem 2014;62(10):751-758

18 Gowda BC, Kokila G, Gopinathan PA, Praveen KS. Picrosirius Red and Polarization Microscopy - A Tool for Gender Differentiation. J Clin Diagn Res 2017;11(01):ZC107-ZC109

19 Zerbinati N, Calligaro A. Calcium hydroxylapatite treatment of human skin: evidence of collagen turnover through picrosirius red staining and circularly polarized microscopy. Clin Cosmet Investig Dermatol 2018;11:29-35

20 Kilonzo MM, Brown SR, Bruhn H, et al. Cost Effectiveness of Stapled Haemorrhoidopexy and Traditional Excisional Surgery for the Treatment of Haemorrhoidal Disease. Pharmacoeconom Open 2018;2(03):271-280

21 Hardy A, Chan CL, Cohen CR. The surgical management of haemorrhoids-a review. Dig Surg 2005;22(1-2):26-33

22 van Tol RR, Kleijnen J, Watson AJM, et al. European Society of ColoProctology: guideline for haemorrhoidal disease. Colorectal Dis 2020;22(06):650-662

23 Candela G, Varriale S, Di Libero L, et al. [The gold standard in the treatment of haemorrhoidal disease. Milligan-Morgan haemorrhoidectomy vs Longo mucoprolapsectomy: comparing techniques]. Minerva Chir 2007;62(03):151-159

24 Fischer AH, Jacobson KA, Rose J, Zeller R. Hematoxylin and eosin staining of tissue and cell sections. CSH Protoc 2008;2008: pdb prot4986.

25 Junqueira LC, Bignolas G, Brentani RR. Picrosirius staining plus polarization microscopy, a specific method for collagen detection in tissue sections. Histochem J 1979;11(04):447-455

26 Junquiera LC, Junqueira LC, Brentani RR. A simple and sensitive method for the quantitative estimation of collagen. Anal Biochem 1979;94(01):96-99

27 Ramos-Vara JA, Miller MA, Dusold DM. Immunohistochemical Expression of CD31 (PECAM-1) in Nonendothelial Tumors of Dogs. Vet Pathol 2018;55(03):402-408

28 Parums DV, Cordell JL, Micklem K, Heryet AR, Gatter KC, Mason DY. JC70: a new monoclonal antibody that detects vascular endothelium associated antigen on routinely processed tissue sections. J Clin Pathol 1990;43(09):752-757

29 Varani J, Dame MK, Rittie L, et al. Decreased collagen production in chronologically aged skin: roles of age-dependent alteration in fibroblast function and defective mechanical stimulation. Am J Pathol 2006;168(06):1861-1868

30 Johanson JF, Sonnenberg A. The prevalence of hemorrhoids and chronic constipation. An epidemiologic study. Gastroenterology 1990;98(02):380-386

31 Liu J, Yu W, Liu Y, et al. Mechanical stretching stimulates collagen synthesis via down-regulating SO2/AAT1 pathway. Sci Rep 2016; 6(06):21112

32 Agbo SP. Surgical management of hemorrhoids. J Surg Tech Case Rep 2011;3(02):68-75

33 Joksimovic N, Spasovski G, Joksimovic V, Andreevski V, Zuccari C, Omini CF. Efficacy and tolerability of hyaluronic acid, tea tree oilrepeatsheetsize $212.75,282.55$ and methyl-sulfonyl-methane in a new gel medical device for treatment of haemorrhoids in a double-blind, placebo-controlled clinical trial. Updates Surg 2012;64(03):195-201 